\title{
Superior mesenteric artery syndrome: a unique complication following carboplatin-based chemotherapy
}

This article was published in the following Dove Press journal:

International Medical Case Reports Journal

17 February 2015

Number of times this article has been viewed

\section{Mudit Chowdhary \\ Heer P Pansuria \\ Bilal Farooqi \\ Hemant Goyal}

Department of Internal Medicine, Mercer University School of Medicine, Macon, GA, USA
Correspondence: Mudit Chowdhary Department of Internal Medicine, Mercer University School of Medicine, 707 Pine Street, Macon, GA 3120 I, USA

$\mathrm{Tel}+\mathrm{I} 478$ 30I 5800

Fax +I 478301 584I

Email mu.chowdhary@gmail.com
Abstract: Superior mesenteric artery syndrome (SMAS) is an uncommon condition, attributable to vascular compression of the third part of the duodenum between the superior mesenteric artery and the abdominal aorta. It can present in patients due to mechanical compression or severe weight loss. We present a unique case of SMAS in a patient undergoing carboplatinbased chemotherapy for mesothelioma. An 81-year-old male with mesothelioma was treated with carboplatin-based chemotherapy. He subsequently suffered a progressive, unintentional $18 \mathrm{~kg}$ weight loss and presented acutely with intense epigastric pain, severe nausea, and vomiting. Diagnosis was confirmed by abdominal computed tomography and esophagogram with upper gastrointestinal series, which revealed gastric and duodenal distention and a narrow angle between the superior mesenteric artery and aorta, causing compression of the duodenum. Prompt recognition of this syndrome allowed us to treat our patient successfully and avoid the risks of operative interventions. To our knowledge, this is the first reported case of SMAS in patients receiving carboplatin. Furthermore, this case of SMAS was unique in that it was due to weight loss as compared with mechanical obstruction. Our experience illustrates the importance of considering SMAS in chemotherapy patients, especially those with substantial weight loss. A high index of suspicion for this potential complication coupled with appropriate radiographic studies are necessary for early diagnosis and can prevent severe consequences.

Keywords: superior mesenteric artery syndrome, mesothelioma, carboplatin, chemotherapy

\section{Introduction}

Superior mesenteric artery syndrome (SMAS) is a rare gastrovascular disorder resulting in proximal intestinal obstruction. Affected patients are characterized by a decreased angle between the overlaying superior mesenteric artery and underlying abdominal aorta, resulting in compression of the third portion of the duodenum. ${ }^{1}$

This rare syndrome typically occurs secondary to rapid weight loss. ${ }^{2}$ Significant weight loss decreases the amount of retroperitoneal fat between the superior mesenteric artery and aorta, thus removing a major source of cushioning for the duodenum and allowing duodenal compression. Weight loss can be attributed to a number of causes, including dietary disorders such as: anorexia nervosa or malabsorption; severe wasting states such as burns, cachexia, and endocrine disorders; spinal deformity due to scoliosis or severe trauma; mechanical compression due to retroperitoneal tumors; and even bariatric surgery. ${ }^{1-12}$

Early diagnosis of SMAS is vital as any delay can result in severe complications, including electrolyte abnormalities, fatal catabolysis, peritonitis, and gastric perforation. ${ }^{2,13}$ Despite the numerous etiologies known, systemic chemotherapy has 
rarely been reported as a cause of SMAS. Here we present a case of a patient with mesothelioma undergoing treatment with carboplatin-based chemotherapy whose course was complicated by the development of SMAS.

\section{Case report}

A previously asymptomatic 81-year-old Caucasian male presented to the emergency room complaining of multiple episodes of bilious, projectile, non-bloody vomiting accompanied by severe nausea and continuous, colicky epigastric pain of 2 days' duration. His past medical history was significant for hypertension and mesothelioma, for which the patient was being treated with a combination of carboplatin and pemetrexed over the past year. The patient denied any similar gastrointestinal symptoms during the course of his chemotherapy; however, he did report an unintentional $18 \mathrm{~kg}$ weight loss over the past 6 months. Additionally, the patient reported no weight loss or gastrointestinal symptoms prior to initiation of his chemotherapy.

On arrival, the patient appeared ill and cachectic, and was in apparent distress. He was afebrile, with pulse of 62 beats per minute and blood pressure of 135/69 mmHg. Physical examination was notable for abdominal tenderness in all quadrants with guarding, along with epigastric bulging. Laboratory data were unremarkable apart from low $\mathrm{K}^{+}$at $3.3 \mathrm{mEq} / \mathrm{L}$.

The patient's symptoms were initially thought to be a side effect from his chemotherapy and he was thus treated conservatively with intravenous fluids, with no resolution of his symptoms. Subsequently, the patient underwent computed tomography of the abdomen (Figures 1 and 2), which revealed considerable gastric and duodenal distention extending to the level of the third/fourth duodenal segment, suggestive of small bowel obstruction, and narrowing of the angle between the superior mesenteric artery and abdominal aorta (less than $20^{\circ}$, reference angle is $45^{\circ}-65^{\circ}$ ). Additionally, no definitive mass was discernible. An esophagogram with upper gastrointestinal series confirmed gastric and proximal duodenal dilatation (megaduodenum) until the third duodenal portion near the midline, where there was short segment narrowing giving way to more caliber at the distal duodenum and proximal small bowel at the ligament of Treitz with a delayed passage of contrast (Figure 3). These findings were consistent with SMAS. The surgeons and gastroenterologists were consulted and conservative management was agreed upon due to the patient's age and state of malnutrition.

The patient was kept nil per os on total parenteral nutrition and intravenous fluids for 2 days, upon which

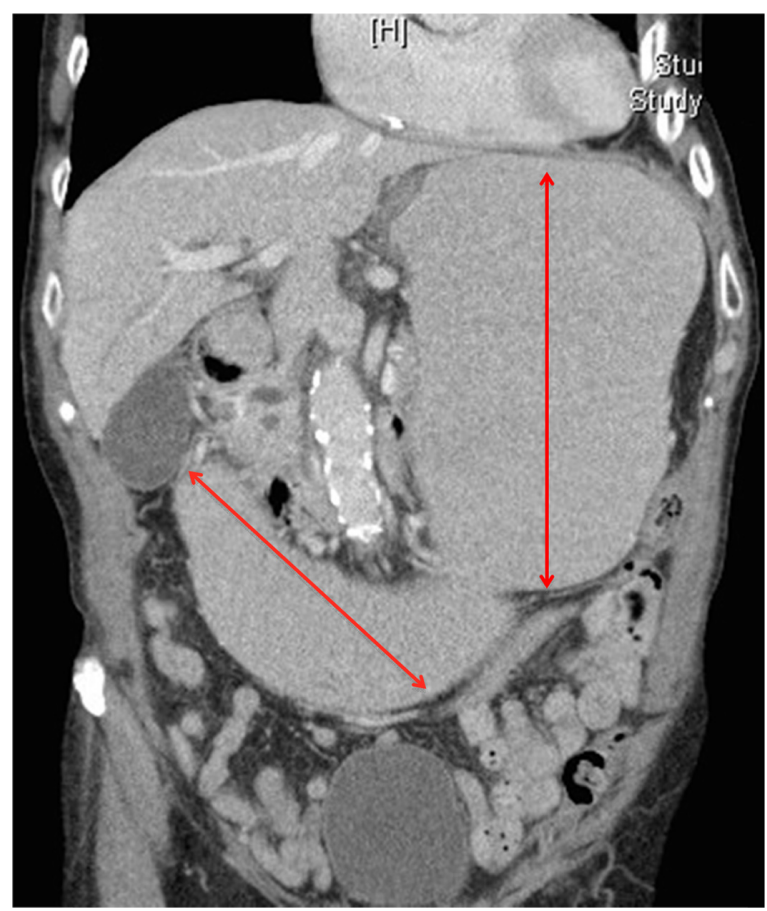

Figure I Computed tomography of the abdomen showing gastric and duodenal distention (red arrows) suggestive of small bowel obstruction and narrowing of the angle between the superior mesenteric artery and the abdominal aorta.

diet was advanced with no further complications. Prior to discharge, the patient was extensively counseled on diet modification to small frequent meals and how to maintain knee-to-chest position after eating. Additionally, the importance of weight gain was discussed. He was discharged home and told to follow up as an outpatient in the following months. The patient gained approximately $5 \mathrm{~kg}$ over a period of 3 months and his symptoms resolved.

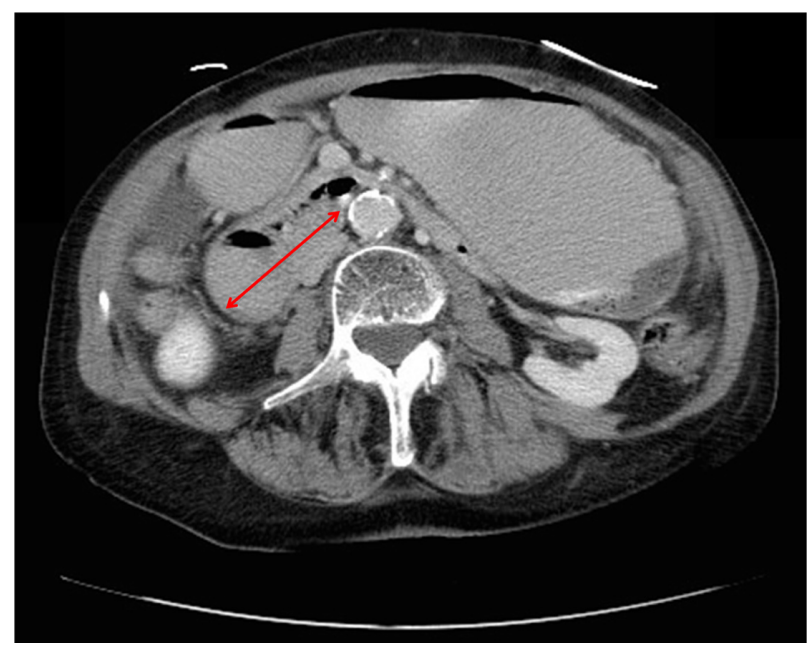

Figure 2 Computed tomography of the abdomen showing gastric and duodenal distention (red arrow) indicating obstruction at the level of the superior mesenteric artery. 


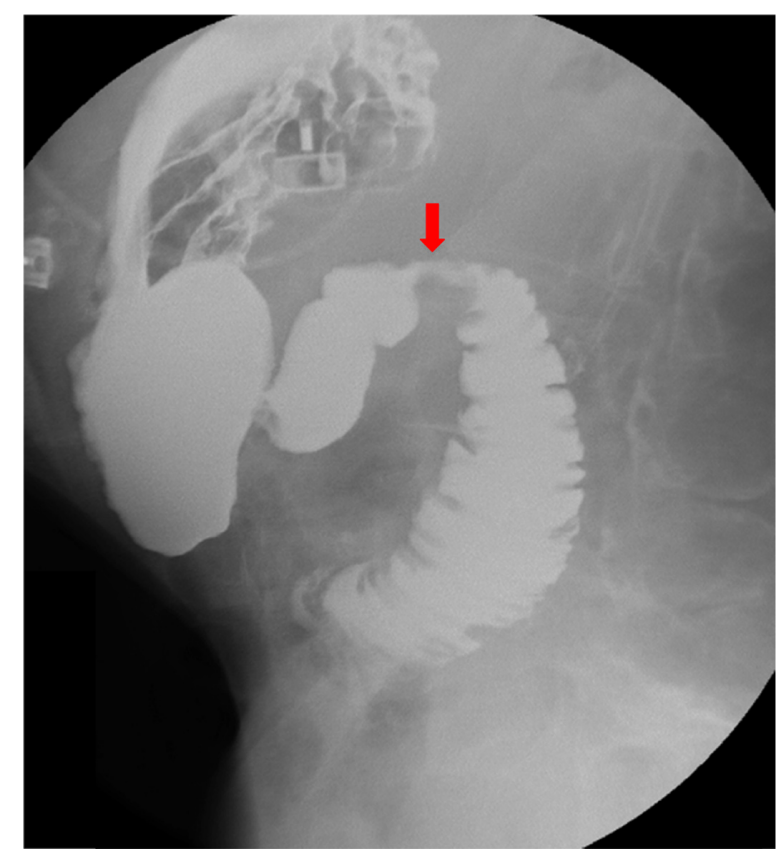

Figure 3 Upper gastrointestinal series. Impression of the third part of the duodenum suggestive of superior mesenteric artery syndrome (red arrow).

\section{Discussion}

SMAS, also known as Wilkie's syndrome or Cast syndrome, is an extremely rare form of upper gastrointestinal obstruction thought to be caused by intermittent obstruction of the third, or transverse, part of the duodenum between the superior mesenteric artery and abdominal aorta. ${ }^{1,3}$ Vascular compression has been noted at all ages, but this syndrome is seen primarily in adolescents or young adults, with females more frequently affected than males. ${ }^{3,4}$

Von Rokitansky first documented the existence of this syndrome in $1861,{ }^{5}$ but it was Wilkie who formally characterized SMAS in $1927 .{ }^{6}$ Despite prior reports and radiological evidence to support the diagnosis, there has been continued skepticism on the existence of SMAS. Responses have varied from whether SMAS is a real entity ${ }^{7}$ to suggestions that SMAS is overdiagnosed. ${ }^{8}$ Nevertheless, SMAS is a well recognized but uncommon clinical entity, with previous studies reporting the incidence of SMAS in the general population to be as low as $0.1 \%-0.3 \% .{ }^{4}$ Precipitating factors for SMAS include profound weight loss due to, but not limited to, eating disorders, prolonged immobilization, or spinal disease, including scoliosis and exaggerated lumbar lordosis. Additionally, constitutional factors such as a tall, thin, body build, and anatomic anomalies including an abnormally high and fixed position of the ligament of Treitz with an upward displacing duodenum or a low origin of the superior mesenteric artery have also been implicated. ${ }^{2,3,14}$
Our patient presented with several risk factors for SMAS, most significantly a recent history of considerable weight loss following chemotherapy. Neoplasms and systemic chemotherapy are well known risk factors for weight loss, but a PubMed literature search revealed only one previously reported case of SMAS in a cancer patient being treated with chemotherapy. ${ }^{15}$ Moreover, cases involving SMAS in cancer patients were caused by mechanical compression of the duodenum by the tumor rather than weight loss itself. In the case reported by Ushiki et al, the patient was being treated with cisplatin, a drug strongly associated with severe emesis. ${ }^{15}$

Carboplatin, similar to its parent compound cisplatin, is a platinum-based antineoplastic drug used in the treatment of lung cancers. Unlike its predecessor, carboplatin is known for its greatly reduced side effect profile and is thus preferred in patients unable to tolerate toxicities, along with the elderly. The most common complications associated with carboplatin are myelosuppression, anemia, and mild nausea and vomiting soon after initial use. ${ }^{16}$ However, this scenario was not the case in our patient. He did not have any episodes of emesis prior to his acute presentation. Nevertheless, systemic side effects such as weight loss with carboplatin are noteworthy. Our patient developed weight loss as a result of receiving carboplatin-based chemotherapy, which subsequently led to SMAS.

It is likewise notable that our patient did not report any weight loss prior to initiation of his chemotherapy. Nevertheless, it is likely that the combination of carboplatinbased chemotherapy and the primary malignancy led to our patient's weight loss. When a search for SMAS in patients with mesothelioma is performed, the results do not show any reported cases. We believe our case is the first reported one. What is unique about our case is the fact that the patient presented with SMAS due to weight loss and not mechanical obstruction. There was no evidence of tumor or metastasis in the area of the superior mesenteric artery. The weight loss induced in this patient, whether by the cancer or the subsequent chemotherapy, is thought to have been the cause of the SMAS. Further evidence of weight loss being the inducing factor of the SMAS is the fact that our patient presented in follow-up with weight gain and no further episodes.

In conclusion, SMAS is a rare but treatable complication in patients receiving carboplatin-based chemotherapy. Practitioners should be aware of this potential complication and educate patients to report any significant weight loss to their physician. SMAS should be considered a differential diagnosis in patients who present with severe abdominal pain, 
especially after weight loss, regardless of the etiology. We also encourage clinicians to keep a high index of suspicion for this condition as delays in diagnosis can lead to a recurrence of symptoms, leading to increased weight loss and the formation of a vicious cycle, along with potentially fatal complications. Once symptom-free, patients should undergo extensive dietary and postural counseling in order to gain weight and prevent further exacerbations.

\section{Disclosure}

The authors report no conflicts of interest in this work.

\section{References}

1. Gustafsson L, Falk A, Lukes PJ, Gamklou R. Diagnosis and treatment of superior mesenteric artery syndrome. Br J Surg. 1984;71: 499-501.

2. Alsulaimy M, Tashiro J, Perez EA, Sola JE. Laparoscopic Ladd's procedure for superior mesenteric artery syndrome. J Pediatr Surg. 2014;49: $1533-1535$.

3. Raissi B, Taylor BM, Taves DH. Recurrent superior mesenteric artery (Wilkie's) syndrome: a case report. Can J Surg. 1996;39:410-416.

4. Shiu JR, Chao HC, Luo CC, et al. Clinical and nutritional outcomes in children with idiopathic superior mesenteric artery syndrome. J Pediatr Gastroenterol Nutr. 2010;51:177-182.

5. Von Rokitansky C. [Textbook of Pathological Anatomy]. Vienna, Austria: Braumuller and Seidel; 1861. German.

6. Wilkie DP. Chronic duodenal ileus. Am J Med Sci. 1927;173:643-650.
7. Cimino CV. Arteriomesenteric occlusion of the duodenum: an entity? Radiology. 1961;76:828-829.

8. Hines JR, Gore RM, Ballantyne GH. Superior mesenteric artery syndrome - diagnostic criteria and therapeutic approaches. Am J Surg. 1984;148:630-632.

9. Shetty AK, Schmidt-Sommerfeld E, Haymon ML, Udall Jr JN. Radiological case of the month. Denouement and discussion: superior mesenteric artery syndrome. Arch Pediatr Adolesc Med. 1999;153: 303-304.

10. Mansberger AR, Hearn JB, Byers RM, Fleisig N, Buxton RW. Vascular compression of the duodenum: emphasis on accurate diagnosis. Am J Surg. 1968;115:89-95.

11. Cohen LB, Field SP, Sachar DB. The superior mesenteric artery syndrome: the disease that isn't, or is it? J Clin Gastroenterol. 1985;7: 113-116.

12. Welsch T, Buchler MW, Kienle P. Recalling superior mesenteric artery syndrome. Dig Surg. 2007;24:149-156.

13. Ko KH, Tsai SH, Yu CY, Huang GS, Liu CH, Chang WC. Unusual complication of superior mesenteric artery syndrome: spontaneous upper gastrointestinal bleeding with hypovolemic shock. J Chin Med Assoc. 2009;72:45-47.

14. Kim S, Kim YS, Min YD. SMA syndrome treated by single incision laparoscopic duodenojejunostomy. Clin Med Insights Case Rep. 2014;7:87-89.

15. Ushiki A, Koizumi T, Yamamoto H, Hanaoka M, Kubo K, Matsushita M. Superior mesenteric artery syndrome following initiation of cisplatin-containing chemotherapy: a case report. J Med Case Rep. 2012;6:14.

16. Carteni G, Manegold C, Martin Garcia C, et al. Malignant peritoneal mesothelioma - results from the International Expanded Access Program using pemetrexed alone or in combination with a platinum agent. Lung Cancer. 2009;64:211-218.
International Medical Case Reports Journal

\section{Publish your work in this journal}

The International Medical Case Reports Journal is an international, peer-reviewed open-access journal publishing original case reports from all medical specialties. Previously unpublished medical posters are also accepted relating to any area of clinical or preclinical science. Submissions should not normally exceed 2,000 words or

\section{Dovepress}

4 published pages including figures, diagrams and references. The manuscript management system is completely online and includes a very quick and fair peer-review system, which is all easy to use. Visit $\mathrm{http}: / /$ www.dovepress.com/testimonials.php to read real quotes from published authors. 